\title{
Anatomic Considerations of Anterior Transarticular Screw Fixation for Atlantoaxial Instability
}

\author{
Sandeep Sonone ${ }^{1}$, Aditya Anand Dahapute ${ }^{1}$, Chaitanya Waghchoure ${ }^{1}$, \\ Nandan Marathe ${ }^{1}$, Swapnil Anil Keny ${ }^{1}$, Kritarth Singh ${ }^{2}$, Rohan Gala ${ }^{1}$ \\ ${ }^{1}$ Department of Orthopaedics, Seth GS Medical College and KEM Hospital, Mumbai, India \\ ${ }^{2}$ Department of Pharmacology, Seth GS Medical College and KEM Hospital, Mumbai, India
}

\section{Study Design: Cadaveric and observational study.}

Purpose: Atlantoaxial instability (AAI) is characterized by excessive movement at the C1-C2 junction between the atlas and axis. An anterior surgical approach to expose the upper cervical spine for internal fixation and bone grafting has been developed to fix AAI. Currently, no anatomic information exists on the anterior transarticular atlantoaxial screw or screw and plate fixation between $\mathrm{C} 1$ and $\mathrm{C} 2$ in the Indian population. The objective of this study is to assess the anatomic landmarks of C1-C2 vertebrae: entry point, trajectory, screw length, and safety of the procedure.

Overview of Literature: Methods outlined by Magerl and Harms are the optimal approaches among the dorsal techniques. Contraindications for these techniques include aberrant location of vertebral arteries, fractures of C1-C2 posterior structures. In these cases, anterior transarticular fixation is an alternative. Several available screw insertion trajectories have been reported. Biomechanical studies have demonstrated that adequate rigidity of this fixation is comparable with posterior fusion techniques.

Methods: Direct measurements using Vernier calipers and a goniometer were recorded from 30 embalmed human cadavers. The primary parameters measured were the minimum and maximum lateral and posterior angulations of the screw in the sagittal and coronal planes, respectively, and optimum screw length, if it was placed accurately.

Results: The posterior and lateral angles of screw placement in the coronal and sagittal planes ranged from $16^{\circ}$ to $30^{\circ}$ (mean \pm standard deviation [SD], $\left.23.93^{\circ} \pm 3.93^{\circ}\right)$ and $8^{\circ}$ to $17^{\circ}\left(\right.$ mean $\left.\pm S D, 13.3^{\circ} \pm 2.26^{\circ}\right)$, respectively. The optimum screw length was $25-38 \mathrm{~mm}$ (mean $\pm S D, 28.76 \pm 3.69 \mathrm{~mm}$ ).

Conclusions: If the screw was inserted without lateral angulation, the spinal canal or cord could be violated. If a longer screw was inserted with greater posterior angulation, the vertebral artery at the posterior or posterolateral aspect of the $\mathrm{C} 1$ superior facet could be violated. Thus, $26^{\circ}$ and $30^{\circ}$ of lateral and posterior angulations, respectively, are the maximum angles permissible to avoid injury of the vertebral artery and violations of the spinal canal or atlanto-occipital joint.

Keywords: Atlantoaxial instability; Transarticular screw; Cadaveric

Received Jan 11, 2019; Revised Feb 19, 2019; Accepted Apr 13, 2019

Corresponding author: Aditya Dahapute

Department of Orthopaedics, MSB 6th floor, KEM Hospital, Parel, Mumbai-400 012, Maharashtra, India

Tel: +91-8600600446, E-mail: adityadahapute1986@gmail.com 


\section{Introduction}

Atlantoaxial instability (AAI) is characterized by excessive movement at the junction between the atlas $(\mathrm{C} 1)$ and axis (C2) as a result of bony or ligamentous abnormality. Various methods for $\mathrm{C} 1-\mathrm{C} 2$ fixation include posterior methods with interlaminar clamps, wiring techniques, transarticular screw placement, and pedicle screw fixation. AAI caused by trauma or congenital malformation usually requires $\mathrm{C} 1 / 2$ arthrodesis. Posterior transarticular screw fixation with wiring techniques or laminar clamps is widely used by surgeons and considered the gold standard for $\mathrm{C} 1 / 2$ fusion [1-3]. However, the complicated structures of atlantoaxial complex deem surgery for this region as high risk. Elgafy et al. [4] have reported that 10\%-23\% of patients who require atlantoaxial arthrodesis have anatomic variations of the vertebral artery on at least one side and are not suitable for posterior transarticular screw fixation. The rate reported by Lau et al. [5] is approximately $40 \%$.

In 1997, anterior transarticular screw (ATS) fixation for atlantoaxial joint instability was first described by Barbour [6]. In 1998, Lu et al. [7] conducted an anatomic study for ATS fixation. Till 2003, no additional studies had been reported on the topic until Reindl et al. [8] demonstrated the technique using a standard Smith-Robinson approach.

This approach has several advantages over other methods of AAI management. ATS fixations require only a single approach for anterior soft tissue release, decompression, reduction of the $\mathrm{C} 1-\mathrm{C} 2$ vertebrae, and fixation through the same approach along with freshening of the atlantoaxial joint and placement of autologous bone graft, thus avoiding the posterior neck approach. The surgical approach is far less traumatic and exploits a virtual space rather than dissection through a muscle, thereby decreasing the infection rate. However, this approach leaves a more cosmetically acceptable scar remains. The approach also decreases the risk of vertebral artery injury because the starting point is closer to the vertebral artery foramen; therefore, the screw path is easier to control. Additionally, the occipital condyles limit potential migration of a Kirschner wire or placement of a long screw that would otherwise risk injuring the adjacent nervous structures. Finally, in the setting of trauma, positioning of the patient is simpler and is preferred for an unstable cervical spine. This approach is an option in the cases of irreducible at- lantoaxial dislocation where anterior release can be combined with anterior fixation, keeping the posterior tension band and muscle attachments of $\mathrm{C} 2$ intact.

After an extensive literature research, no anatomic information was found regarding the anterior transarticular atlantoaxial screw or screw and plate fixation between $\mathrm{C} 1$ and C2. These anatomic landmarks must be decided so that AAI fixation can be applied successfully in patients. Thus, we conducted a cadaveric study to assess the anatomic landmarks of the $\mathrm{C} 1-\mathrm{C} 2$ vertebrae, the screw entry point, trajectory, and length, and safety of the procedure in cervical spines of the Indian population. This study was conducted to aid in the safe and accurate ATS fixation for AAI.

\section{Materials and Methods}

The study was carried out at Seth G.S. Medical College \& K.E.M. Hospital in 30 human embalmed cadavers. Ethics committee approval was obtained before initiating the study. Since it was a cadaveric study we obtained a consent waiver for this study. The parameters related to anterior transarticular atlantoaxial screw fixation or screw and plate fixation between the $\mathrm{C} 1$ lateral mass and $\mathrm{C} 2$ vertebral body were recorded using Vernier calipers and a goniometer as direct measurements. The anterior transarticular $\mathrm{C} 1-\mathrm{C} 2$ screw insertion point was at the junction of the lateral edge of the $\mathrm{C} 2$ vertebral body to $4 \mathrm{~mm}$ above the inferior edge of the $\mathrm{C} 2$ anterior arch.

First, the cervical spine was dissected anteriorly by removing the larynx and pharynx up to the longus coli

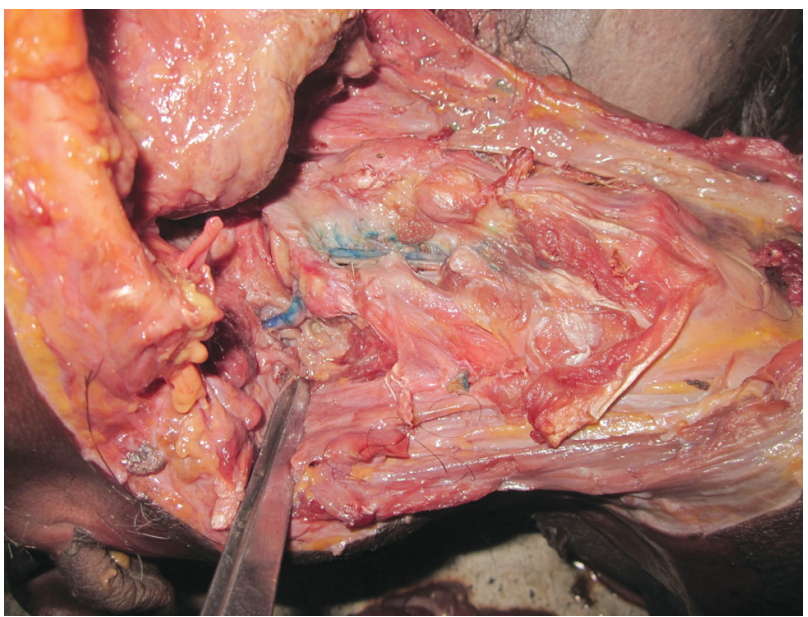

Fig. 1. Disarticulated cadaveric specimen showing the course of the vertebral artery. 


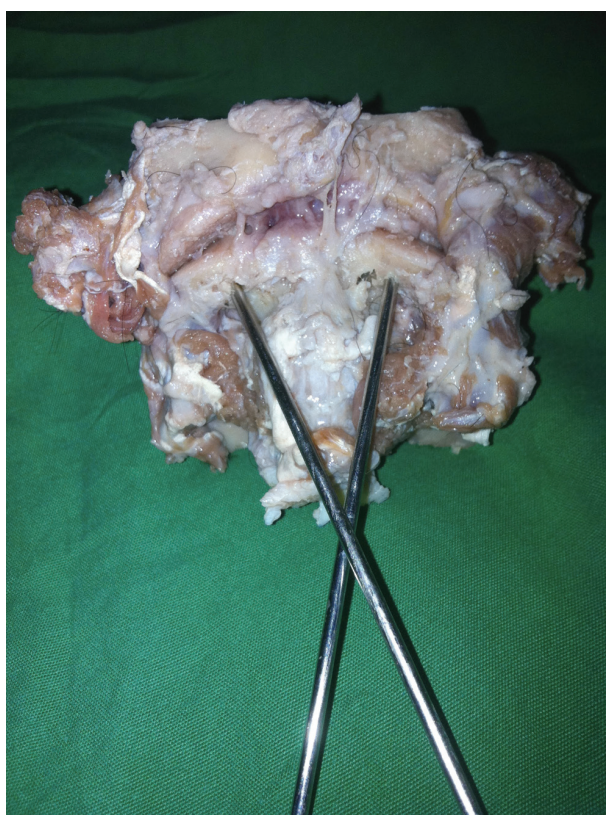

Fig. 2. Cadaveric specimen showing disarticulated C1-C2.

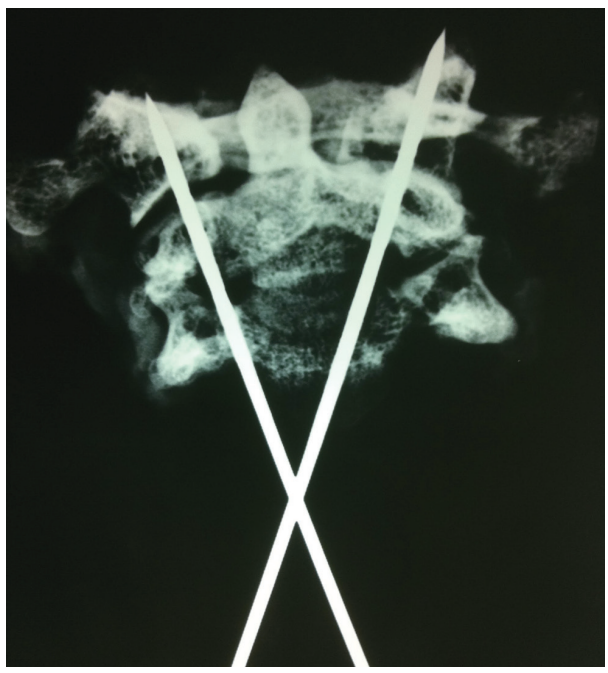

Fig. 3. Anteroposterior view of disarticulated C1-C2 muscles. The course of the vertebral arteries was bilaterally dissected (Fig. 1) in the transverse foramen from the C3 vertebra from below upwards. Next, the distance of the vertebral arteries at the $\mathrm{C} 2$ level from the entry point on C2 was measured using Vernier calipers. The entire course of the vertebral arteries was then posteriorly traced upwards over the $\mathrm{C} 1$ arch into the foramen magnum. Thereafter, the parameters of the $\mathrm{C} 1-\mathrm{C} 2$ facets were measured as the anteroposterior diameter of the inferior facet of $\mathrm{C} 1$ and superior facet of $\mathrm{C} 2$ using Vernier calipers. Moreover, the vertical height of the $\mathrm{C} 1$ lateral mass was measured.

A concavity of the anterior cortex of the $\mathrm{C} 2$ arch consistently found in all specimens served as an anatomic landmark ( $4 \mathrm{~mm}$ above the inferior edge of the $\mathrm{C} 2$ arch at the lateral border of the $\mathrm{C} 2$ vertebral body) for the entry point of ATS fixation. Kirschner wires were placed from the entry point using a drill directed laterally and posteriorly toward the $\mathrm{C} 1-\mathrm{C} 2$ facet joints on the same side (Fig. 2). The position and trajectory of the wires were radiologically confirmed (Fig. 3). The corresponding minimum and maximum angulations of the screw path relative to the sagittal and coronal planes were determined. The maximum posterior angulation of screw placement relative to the coronal plane was also determined. The exit point of the wire was then assessed by disarticulating the atlantooccipital joint. To place the transarticular screw, the length of the wire was measured using Vernier calipers.

Statistical analysis was performed using Graphpad InStat software (GraphPad Software, San Diego, CA, USA) and the parameter values were represented as means \pm standard deviation (SD).

\section{Results}

The primary parameters measured were the minimum

Table 1. Cadaveric variables related to anterior transarticular atlantoaxial screw fixation or screw and plate fixation between the C1 lateral mass and the C2 vertebral body

\begin{tabular}{lccc} 
Variable & Maximum & Minimum & Mean \pm standard deviation \\
AP diameter of inferior facet of C1 $(\mathrm{mm})$ & 21 & 16 & $18.41 \pm 1.5$ \\
AP diameter of superior facet of C2 $(\mathrm{mm})$ & 21 & 14 & $18.23 \pm 1.74$ \\
Vertical height of C1 lateral mass $(\mathrm{mm})$ & 22 & 17 & $18.67 \pm 1.54$ \\
Distance of vertebral artery from screw entry point $(\mathrm{mm})$ & 10 & 7 & $9.06 \pm 0.91$ \\
Length of the screw $(\mathrm{mm})$ & 38 & 16 & $28.76 \pm 3.69$ \\
Posterior angle of screw placement in coronal plane $\left(^{\circ}\right)$ & 30 & 8 & $23.93 \pm 3.93$ \\
\hline Lateral angle of screw placement in sagittal plane $\left(^{\circ}\right)$ & 17 & $13.3 \pm 2.26$ \\
\hline
\end{tabular}

AP, anteroposterior. 
and maximum lateral and posterior angulations of the screw in the sagittal and coronal planes, respectively, and the optimum screw length, if placed accurately. The posterior and lateral angles of screw placement in the coronal and sagittal planes ranged from $16^{\circ}$ to $30^{\circ}$ (mean \pm SD, $\left.23.93^{\circ} \pm 3.93^{\circ}\right)$ and $8^{\circ}$ to $17^{\circ}\left(\right.$ mean $\left.\pm \mathrm{SD}, 13.3^{\circ} \pm 2.26^{\circ}\right)$, respectively. The optimum screw length was $25-38 \mathrm{~mm}$ (mean \pm SD, 28.76 $\pm 3.69 \mathrm{~mm}$ ).

The secondary parameters measured were related to the anatomy of the $\mathrm{C} 1-\mathrm{C} 2$ vertebrae and vertebral artery. The anteroposterior diameters of the inferior and superior articular facets of the $\mathrm{C} 1$ and $\mathrm{C} 2$ vertebrae ranged from 16 to $21 \mathrm{~mm}$ (mean \pm SD, $18.41 \pm 1.5 \mathrm{~mm}$ ) and 14 to $21 \mathrm{~mm}$ (mean $\pm \mathrm{SD}, 18.23 \pm 1.74 \mathrm{~mm}$ ), respectively.

The vertical height of the lateral mass of the $\mathrm{C} 1$ vertebra measured at the midpoint of the lateral mass and anterior surface ranged from 17 to $22 \mathrm{~mm}$ (mean, $18.67 \pm 1.54$ $\mathrm{mm})$. The distance of the vertebral artery at the level of the $\mathrm{C} 2$ vertebra from the entry point for screw placement ranged from 7 to $10 \mathrm{~mm}$ (mean $\pm \mathrm{SD}, 9.06 \pm 0.91 \mathrm{~mm}$ ).

Table 1 summarizes the minimum and maximum values of the variables measured using mean $\pm \mathrm{SD}$ values.

\section{Discussion}

Various methods of atlantoaxial fusion have been described. Methods outlined by Magerl and Harms are typically regarded as the optimal approaches among the dorsal techniques $[9,10]$. The incidence of fusion formation among all cases of screw fixation is 93\% [11]. Contraindications for these techniques include the aberrant location of vertebral arteries, fractures of $\mathrm{C} 1-\mathrm{C} 2$ posterior structures, and fractures of $\mathrm{C} 1$ lateral masses. In these cases, anterior transarticular fixation is an alternative to the Magerl and Harms methods. Several available screw insertion trajectories have been reported to date $[8,12,13]$. Biomechanical studies have demonstrated that the adequate rigidity of this fixation is comparable with that of posterior fusion techniques $[14,15]$. No complications associated with the surgical technique have been reported in the literature.

In the current study, we measured minimum and maximum values of the angulation of screw placement relative to the sagittal and coronal planes and lengths of the screw. This cadaveric investigation demonstrated that a screw $>28 \mathrm{~mm}$ increases the chance of violating the superior surface of the $\mathrm{C} 1$ superior facet, possibly leading to trans- fixation of the atlanto-occipital joint.

Anterior screw placement across the $\mathrm{C} 1-\mathrm{C} 2$ facet joint toward the lateral mass of $\mathrm{C} 1$ is invisible to the surgeon. Although a range of angulations of screw placement relative to the sagittal and coronal planes has been provided in the current study, fluoroscopic guidance should be used during surgery to ensure the proper screw trajectory. Therefore, extreme caution should be taken while performing this technique in vivo.

With lateral fluoroscopic monitoring, the drill trajectory was aimed toward the middle- or posterior-third of the $\mathrm{C} 1$ superior facet. Trajectories from $8^{\circ}$ to $17^{\circ}$ laterally and $16^{\circ}$ to $30^{\circ}$ posteriorly are required in the Indian population for transarticular screw fixation. Therefore, this study showed that if a screw is inserted without lateral angulation, the spinal canal or cord can be violated. If a longer screw is inserted with greater posterior angulation, the vertebral artery situated at the posterior or posterolateral aspect of the $\mathrm{C} 1$ superior facet (vertebral artery groove) can be violated; thus, $17^{\circ}$ of lateral and $30^{\circ}$ of posterior angulations are the maximum angles permissible to avoid injury of the vertebral artery and violations of the spinal canal or atlanto-occipital joint.

If maximum purchase of the screws into the $\mathrm{C} 1$ lateral mass is expected, the screws should be inserted as close as possible to the postero-superior edge of the $\mathrm{C} 1$ superior facets. The potential for injury to the vertebral artery should be of concern during this surgical procedure. If rigid fixation of the atlantoaxial joint is expected, two screws can be medially and laterally placed.

The distance of the vertebral artery from the entry point laterally at an average of $9 \mathrm{~mm}$ is safe and accurate for ATS fixation with further avoidance of the risk of vertebral artery injury by placing the screws in a safe trajectory as achieved in this study.

Using this procedure, iatrogenic injury of the cervical cord caused by even minor flexion of the head and morbidity and mortality associated with posterior surgical approaches may be avoided. Removal of the displaced odontoid process for relief of the ventral compression of the spinal cord, decortication of the articular cartilages between the superior and inferior surfaces of the atlantoaxial joints, and release of the locked atlantoaxial joints can be accomplished simultaneously. 


\section{Conclusions}

An anterior transarticular atlantoaxial screw 25- to $38^{-}$ $\mathrm{mm}$ long can be inserted with a lateral angulation of $8^{\circ}-17^{\circ}$ relative to the sagittal plane and a posterior angulation of $16^{\circ}-30^{\circ}$ relative to the coronal plane with the least possibility for iatrogenic injury to the vertebral artery and spinal cord. Anterior atlantoaxial transarticular screw fixation provides an alternative method to achieve stabilization and fusion at $\mathrm{C} 1-\mathrm{C} 2$ vertebrae. This method is applicable in cases where posterior atlantoaxial fusion is not achievable due to anatomical characteristics of patients or if a prone position is undesirable due to concomitant diseases or combined injuries.

\section{Conflict of Interest}

No potential conflict of interest relevant to this article was reported.

\section{Author Contributions}

Study design and concept: Sandeep Sonone; data collection and data analysis: Aditya Dahapute; review of literature: Chaitanya Waghchoure, Nandan Marathe; editing and proof reading: Nandan Marathe, Rohan Gala; and statistics and data analysis: Swapnil Keny, Kritarth Singh.

\section{References}

1. Dickman CA, Sonntag VK. Posterior C1-C2 transarticular screw fixation for atlantoaxial arthrodesis. Neurosurgery 1998;43:275-80.

2. Fuji T, Oda T, Kato Y, Fujita S, Tanaka M. Accuracy of atlantoaxial transarticular screw insertion. Spine (Phila Pa 1976) 2000;25:1760-4.

3. Weidner A, Wahler M, Chiu ST, Ullrich CG. Modification of C1-C2 transarticular screw fixation by image-guided surgery. Spine (Phila Pa 1976) 2000;25:2668-73.

4. Elgafy H, Potluri T, Goel VK, Foster S, Faizan A, Kulkarni N. Biomechanical analysis comparing three C1-C2 transarticular screw salvaging fixation techniques. Spine (Phila Pa 1976) 2010;35:378-85.

5. Lau SW, Sun LK, Lai R, et al. Study of the anatomi- cal variations of vertebral artery in C2 vertebra with magnetic resonance imaging and its application in the C1-C2 transarticular screw fixation. Spine (Phila Pa 1976) 2010;35:1136-43.

6. Barbour JR. Screw fixation in fracture of the odontoid process. S Aust Clin 1971;5:20.

7. Lu J, Ebraheim NA, Yang H, Heck BE, Yeasting RA. Anatomic considerations of anterior transarticular screw fixation for atlantoaxial instability. Spine (Phila Pa 1976) 1998;23:1229-35.

8. Reindl R, Sen M, Aebi M. Anterior instrumentation for traumatic C1-C2 instability. Spine (Phila Pa 1976) 2003;28:E329-33.

9. Greene KA, Dickman CA, Marciano FF, Drabier JB, Hadley MN, Sonntag VK. Acute axis fractures: analysis of management and outcome in 340 consecutive cases. Spine (Phila Pa 1976) 1997;22:1843-52.

10. Jacobson ME, Khan SN, An HS. C1-C2 posterior fixation: indications, technique, and results. Orthop Clin North Am 2012;43:11-8.

11. Elliott RE, Tanweer O, Boah A, et al. Outcome comparison of atlantoaxial fusion with transarticular screws and screw-rod constructs: meta-analysis and review of literature. J Spinal Disord Tech 2014;27:1128.

12. Koller H, Kammermeier V, Ulbricht D, et al. Anterior retropharyngeal fixation C1-2 for stabilization of atlantoaxial instabilities: study of feasibility, technical description and preliminary results. Eur Spine J 2006;15:1326-38.

13. Ji W, Zheng M, Tong J, et al. Feasibility and trajectory study of anterior transarticular crossing screw placement for atlantoaxial joint instability: a cadaveric study and description of a novel technique. Eur Spine J 2015;24:2954-60.

14. Sen MK, Steffen T, Beckman L, Tsantrizos A, Reindl $\mathrm{R}$, Aebi M. Atlantoaxial fusion using anterior transarticular screw fixation of C1-C2: technical innovation and biomechanical study. Eur Spine J 2005;14:512-8.

15. Lapsiwala SB, Anderson PA, Oza A, Resnick DK. Biomechanical comparison of four $\mathrm{C} 1$ to $\mathrm{C} 2$ rigid fixative techniques: anterior transarticular, posterior transarticular, $\mathrm{C} 1$ to $\mathrm{C} 2$ pedicle, and $\mathrm{C} 1$ to $\mathrm{C} 2$ intralaminar screws. Neurosurgery 2006;58:516-21. 